DOI: http://doi.org/10.4038/kjm.v6i2.7542

\title{
Emotional Works and Turnover Intention of Sri Lankan Nurses
}

\author{
M.K. Dinithi Padmasiri ${ }^{1}$, A.M.T. Lakmali ${ }^{2}$ \\ Department of Human Resource Management, Faculty of Commerce and Management \\ Studies, University of Kelaniya, Sri Lanka. \\ 1dinithipadmasiri@kln.ac.lk, ${ }^{2}$ amtlakmali@gmail.com
}

\begin{abstract}
In the quest for the concept of emotional work, it is apparent that comparing to the international context there are much less research done in Sri Lanka. Thus, by filling the existing gap this study analyses the relationship between emotional works and turnover intention of nurses. The problem of the study was to find out whether there is a relationship exists between emotional works and turnover intention of nurses in Sri Lanka. This study applied quantitative and a cross-sectional survey design where data was collected through a structured questionnaire. Random sampling technique was applied to select the sample of 170 nurses in a selected district. Findings revealed that emotional works; surface acting and deep acting are significantly positively related to turnover intention. Meanwhile, findings verified that as a whole there is a significant positive relationship between emotional works and turnover intention of nurses in Sri Lanka. The present study updates the current literature in the arena of emotional works.
\end{abstract}

Keywords: Emotional Works, Turnover Intention, Surface Acting, Deep Acting, Nurses

\section{Introduction}

Employee turnover refers to the phenomena of employees leaving an organization voluntarily (Shaw, 2005). According to Feldman (1994), professional turnover refers to an employee's withdrawal from a profession, even after a long-standing career. To date, determinants of turnover and its correlates have been widely examined in the management literature. The reason for such close examination is turnover impacts the bottom-line of the organization (Hinkin \& Tracey, 2000).

In addition, turnover defined as the voluntary separation of an individual from an organization, which is particular importance in nursing because of the high turnover rate of nurses (Price \& Mueller, 1986). This high turnover of nurses is significant because it results in high costs to the

${ }^{1}$ http://orcid.org/0000-0001-7289-120X

Kelaniya Journal of Management | 2017 | Vol. 06 | Issue 02 | Page 1 
hospital administration and added stress on the nursing staff, and ultimately, it may negatively affect the quality of care that the patient receives.

This study focuses more on turnover intentions than on actual turnover behaviors. Turnover intention is claimed to start with psychological responses to negative aspects of organizations or jobs. The core of the process includes the cognitive component involving decision to leave, and withdrawal behavior which may be categorized as withdrawal from the current job or actions oriented to future opportunities (Takase, 2010). According to Bergiel, Nguyen, Clenny and Taylor (2009), the turnover intention is a kind of obvious and hidden behavioral and attitudinal tendency to change the job and an organization. Many studies related to nurses have shown that intentions to leave are a better prediction for withdrawal behavior (Hayes et al., 2006). Further they have indicated that employee disengages from work due to high incivility, job burnout is likely to occur which may lead to turnover intention.

Krausz (1995) asserted that studies among nurses have shown that intentions to leave are a better predictor of actual turnover than are attitudinal measures. Moreover, they argued that studies using intentions as the criterion have distinct advantages over those using behavior as the dependent variable. First, behaviors are often influenced by a host of other variables (company policies, economic conditions) that cannot be controlled by the investigator but influences the findings. Second, turnover research has shown that a person's self-expressed intentions are the best predictor of turnover (Steel \& Ovalle, 1984). Moreover, Price and Mueller (1986) argued that expressed intentions of leaving a job are an expression of an emotional response toward work or the profession. Parasuraman (1989) has claimed that turnover among staff nurses asserted and intentions play a key mediating role between attitudes and turnover and are the immediate determinant of actual turnover.

Therefore, the main purpose of this study is to identify the relationship between emotional works and turnover intention of nurses. To address this main purpose, the objectives of the study are: (a) to find the relationship between emotional works; surface acting and deep acting and turnover intention, (b) to investigate the experience on the job, age and marital status of nurses, (c) to investigate the different levels of emotional works, and (d) to investigate the different level of turnover intention.

This study will contribute to the existing knowledge on emotional works. Especially in the Sri Lankan context this research topic is yet to be discussed. Therefore, it's important to conduct the research in this area in order to identify the relationship between emotional works and 
turnover intention of nurses in the Sri Lankan context. In addition, this study will update the available literature also which will help to academicians to get understanding the relative effectiveness of emotional works and the relationship between emotional works and turnover intention. Furthermore, findings of this study will lead to further research on the field of emotional work and turnover intention. This study is very significant to practitioners such as administrative officers, managers and etc. in Human Resource Management (HRM) because recommendations of the study will be benefited to reduce the turn over intention of nurses since this study will investigate the relationship between emotional works (nurses) and turnover intention. In addition, the policy planning, decision making process and other activities of HR system will be increased through the findings of this research.

\section{Literature Review}

People regard emotion as a value-laden concept which is often treated as "inappropriate" for organizational life. In particular, emotional reactions are often seen as 'disruptive', 'illogical', 'biased' and 'weak'. Emotion, then, becomes a deviation from what is seen as sensible or intelligent linked to the expressive arenas of life, not to the instrumental goal orientation that drives organizations (Putnam \& Mumby, 1993). People "catch" emotions through conscious information processing (such as feeling sad when reading of a tragedy) and/or unconscious or automatic imitation. Emotional contagion may be a very strong constructive or destructive force in organizations (Hatfield, 1992). According to Ashforth and Humphrey (1993), "emotions are an integral and inseparable part of everyday organizational life".

The term of emotional work was first introduced by the American sociologist Arlie Russell Hochschild (Hochschild, 1983). She termed regulation of one's emotions to comply with occupational or organizational norms as "emotional work". Further she defined emotional work as "the management of feeling to create a publicly observable facial and bodily display; emotional work is sold for a wage and therefore has exchange value" (Hochschild, 1983). This definition explicitly delineates that service providers are required to regulate or manage their "feeling" emotions and display those emotions for commercial purpose. According to Hochschild, jobs with emotional works have three criteria. First, they require face-to-face or voice-to-voice contact with the public. Second, they require the worker to produce an emotional state in the client or customer. Third, they allow the employer, through training and supervision, to exercise a degree of control over the emotional activities of employees (Hochschild, 1983). Her research was in the airline industry, and focused particularly on the emotional work of flight attendants. Since the concept of emotional works introduced by 
Hochschild (1983), efforts to refine the concept of emotional works have been made by many researchers (Ashforth \& Humphrey, 1993; Grandey, 2000; Morris \& Feldman, 1996).

The concept of emotion works is an essential factor for individuals to maintain their own selves and smoothly interact with others (Goffman, 1969). Emotional works refers to efforts made to modulate the expression of one's emotions to meet the expectations of employers or customers. These expectations are based on display rules or norms about appropriate emotional expressions for specific situations (Hochschild, 1979; Wharton \& Erickson, 1993; Schaubroeck \& Jones, 2000). Employees who have high levels of customer or client contact in emotional situations, such as nurses, are subject to stronger emotional display rules (Schaubroeck \& Jones, 2000) and consequently greater emotional works.

Further, emotional works can be described as any effort by employees to display behaviours expected by their employer and/or customers that may conflict with their own emotional state (Ashforth \& Humphrey, 1993; Morris \& Feldman, 1996). Emotional works are important in nursing practice (Phillips, 1996) because nurses are often 'emotional jugglers' (Smith \& Gray, 2000) who need to express or suppress their emotions according to what they think their patients and colleagues.

In this study, it has been considered emotional works in a total of two dimensions determined by Cukur (2009) consisting of Deep Acting, Surface Acting. Researchers have empirically shown that the distinction between surface and deep acting may help explain how emotional work can result in both positive and negative outcomes. Surface Acting (SA) involves employees simulating emotions that are not actually felt, by changing their outward appearances (facial expression, gestures, or voice tone) when exhibiting required emotions. Using the surface acting technique, people alter the outward expression of emotion in the service of altering their inner feelings. By changing facial or bodily expressions, such as slumped shoulders, bowed head, of drooping mouth, inner feelings can be altered to a corresponding state (Hochschild, 1983).

Deep Acting (DA) occurs when employees' feelings are not fit with the situation; they then use their training or past experience to work up appropriate emotions. Unlike SA, DA involves changing inner feelings by altering something more than outward appearance. In SA, feelings are changed from "outside in", whereas feelings are changed from the "inside out" in DA (Hochschild, 1983). Further, Hochschild (1983) classified DA as, (1) Exhorting feeling, whereby one actively attempts to evoke or suppress an emotion, (2) Trained 
imagination, whereby one actively invokes thoughts, images, and memories to induce the associated emotion (thinking of a wedding to feel happy or a funeral to feel sad). In other words, employees use their training or past experiences to help conjure up appropriate emotions or responses (empathy, cheerfulness) for a given scene.

However, intentions of the two strategies are definitely different from each other. SA is to make only the visual aspect of employees' emotion correspond to the emotional expression principle of an organization. Accordingly, emotional dissonance could be easily induced (Ashforth \& Humphrey, 1993; Brotheridge \& Grandey, 2002; Zapf, 2002). DA is not only to create externally expressed emotion but to change internal emotion in the direction of the emotional expression principle. For this, empathy, and thoughts and images that trigger specific emotion are actively utilized (Ashforth \& Humphrey, 1993; Brotheridge \& Grandey, 2002; Zapf, 2002).

However, in the Sri Lankan context it is yet to be investigated about emotional works and turnover intention. In recent times most of the research works paid attention to the relationship between emotional works and turnover intention (Brotheridge \& Grandey, 2002; Brotheridge \& Lee, 2002; Grandey, 2000; Grandey, 2003; Grandey et al., 2005; Hom \& Griffeth, 1991). Thus, the purpose of this study is to identify the relationship between emotional works and turnover intention of nurses in Sri Lankan Hospitals. In order to achieve the above purpose, researchers have developed three hypotheses as follows.

$\mathrm{H}_{1}$ : There is a significant relationship between emotional works and turnover intention $\mathrm{H}_{1 \mathrm{a}}$ : There is a significant relationship between surface acting and turnover intention $\mathrm{H}_{1 \mathrm{~b}}$ : There is a significant relationship between deep acting and turnover intention Based on the above hypotheses, the conceptual framework of the study is:

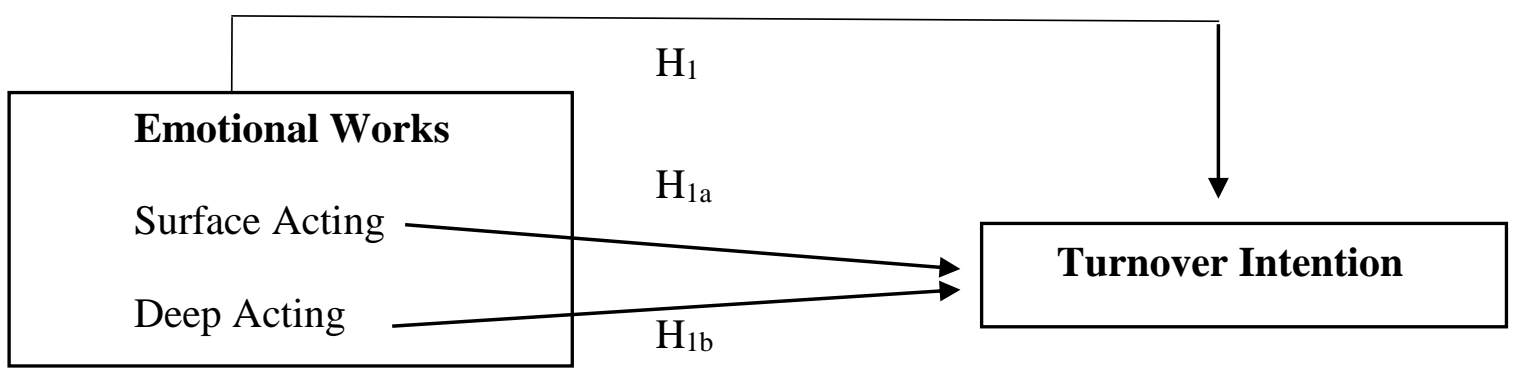

Source: Authors, 2016

Fig 1: Relationships between Emotional Works and Turnover Intention Kelaniya Journal of Management | 2017 | Vol. 06 | Issue 02 | Page 5 


\section{Methodology}

Data was collected from hundred and seventy (170) nurses who are working to hospitals located in one district using the random sampling technique. This study was a cross-sectional study. Since this study is a quantitative deductive study, this study has adapted a survey research method where self-administered questionnaire was used to collect data as a survey instrument. Data was collected through a structured questionnaire developed by Grandey (1999) and Mobley (1979). Data was analyzed by using correlation analysis and simple regression.

\section{Findings}

With the aid of computer based statistical data analysis package, SPSS (Statistical Package for Social Science) English version 20, correlation and regression analysis were used to analyze data. Descriptive statistics for demographics are presented in Table 1.

Table 1: Descriptive statistics for Demographics

\begin{tabular}{|l|l|l|l|}
\hline \multicolumn{2}{|c|}{ Characteristics } & Frequency & Percent\% \\
\hline Age & $20-29$ & 46 & $27 \%$ \\
\cline { 2 - 4 } & $30-39$ & 45 & $26 \%$ \\
\cline { 2 - 4 } & $40-49$ & 38 & $22 \%$ \\
\cline { 2 - 4 } & Above 50 & 41 & $24 \%$ \\
\hline \multirow{4}{*}{ Marital status } & Single & 77 & $45 \%$ \\
\cline { 2 - 4 } & Married & 93 & $55 \%$ \\
\hline Gender & Female & 170 & $100.0 \%$ \\
\hline
\end{tabular}

Cronbach's alpha is the most common measure to test scale reliability. As a rough guide, a value of 0.7 is seen as an acceptable value for Cronbach's alpha (Nunnally 1978). So, in this study the Cronbach's alpha value of emotional works is 0.799 and the Cronbach's alpha value of turnover intention is 0.881 which are in acceptable level (see Table 2). 
DOI: http://doi.org/10.4038/kjm.v6i2.7542

Table 2: Reliability of Construct Measures

\begin{tabular}{|c|l|l|}
\hline Instrument & Cronbach's Alpha & N of items \\
\hline Emotional works & 0.799 & 12 \\
\hline Surface acting & 0.846 & 5 \\
Deep acting & 0.628 & 7 \\
Turnover intention & 0.881 & 3 \\
\hline
\end{tabular}

Source: Survey Data, 2016

\section{Correlation Analysis}

Researchers used correlation analysis and simple regression analysis to test the hypotheses of the study. In order to examine the relationship between independent variable and the dependent variable, tested correlation by using Spearman's rank correlation.

$\mathrm{H}_{1}$ : There is a significant relationship between Emotional Works and Turnover Intention According to the results of the Spearman's correlation shown in the Table 3 , there is a significant relationship between Emotional works and Turnover intention.

Table 3: Correlation between Emotional Works and Turnover Intention

\begin{tabular}{|l|l|l|l|}
\hline \multicolumn{2}{|l|}{} & $\begin{array}{l}\text { Emotional } \\
\text { works }\end{array}$ & $\begin{array}{l}\text { Turnover } \\
\text { intention }\end{array}$ \\
\hline \multirow{4}{*}{ Emotional works } & $\begin{array}{l}\text { Correlation } \\
\text { Coefficient }\end{array}$ & 1.000 & $.545^{* *}$ \\
\cline { 2 - 4 } & Sig. (2-tailed) &. & .000 \\
\cline { 2 - 4 } intention & $\mathrm{N}$ & 70 & 70 \\
\hline \multirow{3}{*}{$\begin{array}{l}\text { Turnover } \\
\text { Correlation }\end{array}$} & $.545^{* *}$ & 1.000 \\
\cline { 2 - 4 } & Sig. (2-tailed) & .000 & 70 \\
\cline { 2 - 4 } & $\mathrm{N}$ & 70 &. \\
\hline
\end{tabular}

** Correlation is significant at the 0.01 level (2-tailed).

Source: Survey data, 2016

Spearman's correlation between the two variables of nurses' is $0.545(p<0.01)$ are positive. It shows that there is a moderate positive relationship between emotional works and turnover 
intention. Thus, $\mathrm{H}_{1}$ could be accepted and it could be concluded that there is a significant relationship between emotional works and turnover intention.

$\mathrm{H}_{1 \mathrm{a}}$ : There is a significant relationship between Surface Acting and Turnover Intention As per the results of the Spearman's correlation shown in the Table 4, there is a significant relationship between surface acting and turnover intention.

Table 4: Correlation between Surface Acting and Turnover Intention

\begin{tabular}{|l|l|l|l|}
\hline \multicolumn{2}{|c|}{} & $\begin{array}{l}\text { Surface } \\
\text { acting }\end{array}$ & $\begin{array}{l}\text { Turnover } \\
\text { intention }\end{array}$ \\
\hline \multirow{3}{*}{ Surface acting } & Correlation Coefficient & 1.000 & $.513^{* *}$ \\
\cline { 2 - 4 } & Sig. (2-tailed) & $\cdot$ & .000 \\
\cline { 2 - 4 } & $\mathrm{N}$ & 70 & 70 \\
\hline \multirow{3}{*}{ Turnover intention } & Correlation Coefficient & $.513^{* *}$ & 1.000 \\
\cline { 2 - 4 } & Sig. (2-tailed) & .000 &. \\
\cline { 2 - 4 } & $\mathrm{N}$ & 70 & 70 \\
\hline
\end{tabular}

**. Correlation is significant at the 0.01 level (2-tailed).

\section{Source: Survey data, 2016}

Spearman's correlation between the two variables of nurses' is $0.513(p<0.01)$ are positive which indicates that there is a moderate positive relationship between surface acting and turnover intention. Hence, $\mathrm{H}_{1 \mathrm{a}}$ could be accepted and it could be concluded that there is a significant relationship between surface acting and turnover intention.

$\mathrm{H}_{1 \mathrm{~b}}$ : There is a significant relationship between Deep Acting and Turnover Intention

According to the results of the Spearman's correlation shown in the Table 5, there is a relationship between deep acting and turnover intention.

Spearman's correlation between the two variables of nurses' is $0.334(p<0.05)$ are positive. It shows that there is a moderate positive relationship between deep acting and turnover intention. It can be concluded that there is a significant relationship between deep acting and turnover intention and hence, $\mathrm{H}_{1 \mathrm{~b}}$ hypothesis was accepted. 
Table 5: Correlation between Deep Acting and Turnover Intention

\begin{tabular}{|l|l|l|l|}
\hline \multicolumn{2}{|l|}{} & $\begin{array}{l}\text { Deep } \\
\text { acting }\end{array}$ & $\begin{array}{l}\text { Turnover } \\
\text { intention }\end{array}$ \\
\hline \multirow{5}{*}{ Deep acting } & Correlation Coefficient & 1.000 & $.334^{* *}$ \\
\cline { 2 - 4 } & Sig. (2-tailed) &. & .005 \\
\cline { 2 - 4 } & $\mathrm{N}$ & 70 & 70 \\
\hline \multirow{5}{*}{ Turnover intention } & Correlation Coefficient & $.334^{* *}$ & 1.000 \\
\cline { 2 - 4 } & Sig. (2-tailed) & .005 &. \\
\cline { 2 - 4 } & $\mathrm{N}$ & 70 & 70 \\
\hline
\end{tabular}

**. Correlation is significant at the 0.01 level (2-tailed).

Source: Survey data, 2016

\section{Simple Regression Analysis}

Simple regression was performed to test the effect of emotional works on turnover intention of nurses. So, the effects of emotional works on turnover intention of nurses was measured with the aid of simple regression model. According to Field (2009), the b value indicates the contribution of each predictor to the model. The standardized beta $(\beta)$ for turnover intention indicates if the effect of the control variable is held constant, there is a positive impact from emotional works on turnover intention of nurses, and the degree of affect it on turnover intention is .505. It means when emotional works of nurses increased by one standard deviation turnover intention of nurses' increase by .505 standard deviations. Statistics relating to the regression testing are depicted in Table 6 and 7.

Table 6: Model Summary

\begin{tabular}{|l|l|l|l|l|}
\hline Model & R & R Square & $\begin{array}{l}\text { Adjusted } \\
\text { R Square }\end{array}$ & $\begin{array}{l}\text { Std. Error } \\
\text { of the } \\
\text { Estimate }\end{array}$ \\
\hline 1 & $.505^{\text {a }}$ & .255 & .244 & .820 \\
\hline \multicolumn{2}{|l|}{ a. Predictors: (Constant), Emotional works } \\
\hline
\end{tabular}

Source: Survey data, 2016 
DOI: http://doi.org/10.4038/kjm.v6i2.7542

Table 7: Simple Regression Statistics of Independent and Dependent Variable

\begin{tabular}{|l|l|l|l|l|l|}
\hline Model & \multicolumn{2}{|l|}{$\begin{array}{l}\text { Unstandardized } \\
\text { Coefficients }\end{array}$} & $\begin{array}{l}\text { Standardized } \\
\text { Coefficients }\end{array}$ & T & Sig. \\
\cline { 2 - 6 } & $\mathrm{B}$ & Std. Error & Beta & & \\
\hline (Constant) & -1.658 & 1.013 & & - & .106 \\
\hline $\begin{array}{l}\text { Emotional } \\
\text { works }\end{array}$ & .941 & .195 & .505 & 4.825 & .000 \\
\hline
\end{tabular}

a. Dependent Variable: Turnover intention

Source: Survey data, 2016

R .505 is the Correlation Coefficient of the independent variable with the dependent variable. $\mathrm{R}$ Square .255 is the explained variance of turnover intention and it was significant at .000 level. The results indicate that $25.5 \%$ of the variance of turnover intention of nurses. Hence, it can be clearly stated that other factors have $74.5 \%$ influences on Turnover intention. Moreover, findings indicated that there is a moderate significant impact of emotional works on turnover intention. Constructed regression equation, where $\mathrm{X}$ stands for emotional works and $\mathrm{Y}$ for turnover intention.

$Y=-1.658+0.941 X$

\section{Conclusion}

The main purpose of this research was to identify the relationship between emotional works and turnover intention of Nurses in Sri Lanka. According to the results of data analysis, all hypotheses could be accepted. As per the findings, $\mathrm{SA}(\beta=0.527, p<0.01)$ and $\mathrm{DA}(\beta=0.231$, $p<0.01)$ are significantly related to turnover intention. In order to reduce the turnover intention of nurses, management could concern about how to manage employees' SA than DA. In the aspect of SA, management could concern to implement work practices to confirm that employees' emotions are actually felt are appeared (facial expression, gestures, or voice tone). In the aspect of DA, management could concern to make sure the employees' feelings fit the situation. Finally, the study specifies that as a whole there was a significant relationship between emotional works and turnover intention of nurses in Sri Lanka. 


\section{Limitations}

One of the limitations is related to the sample which the researchers selected since the sample of the study was nurses in Sri Lanka within one district. Therefore, the data and findings may not be represented the whole Sri Lankan context which is identified as a limitation of the study. Another limitation is, when collecting data through self-administrate method, different respondents' errors were aroused and they distort the real situation of the respondents like understanding questions incorrectly, completing the questionnaire carelessly and intentionally mentioning wrong answers.

\section{Managerial Implications}

Based on the finding researchers can suggest that managers at all levels in hospitals need to ensure the HRM systems, policies, and procedures to promote emotional work practices. Nurses can be trained to use different emotion management strategies for doing job successfully. Finally, the current study suggests that stress management interventions, peer support, mentoring programs and training, and effective communication systems are more significant to reducing the negative effects of emotional works. Accordingly, it is apparent that this study is very significant to practitioners such as administrative officers, managers and etc in Human Resource Management (HRM). So, this study will be benefited to reduce the turn over intention of nurses and improve their effectiveness as well.

\section{Theoretical Implications}

This study contributes to the existing knowledge on emotional works in the Sri Lankan context and in the International context. Especially, this study found the relationship between DA and SA with the turnover intention. Thus, this study brings the literature up-to-date where emotional works as a classified concept (DA and SA). Though, turnover intention is a familiar topic in the research filed, this study investigated the turnover intention of special category of employee who called as emotional workers. Therefore, this study contributed to the knowledge by exploring the new concept emotional works with the dependent variable turnover intention.

\section{Directions for Future Research}

This study has done by using a very limited population (one district) due to the accessibility. Therefore, future researchers can be moved towards a considerable population and to a wide area of hospitals by expanding the sampling frame. Moreover, it is better if future researchers 
DOI: http://doi.org/10.4038/kjm.v6i2.7542

can pay attention more on mix method rather than the quantitative method as emotional works concept is more sensitive concept. Also, this is a human behavioural study which should be done by getting human opinions. Therefore, most of the essential data and ideas can be extracted by using qualitative analysis in future studies.

\section{References}

Ashforth, B., \& Humphrey, R. (1993). Emotional labour in service roles: the influence of identity. Academy of Management Review, 18(1), 88-115

Bergiel, E. B., Nguyen, V. Q., Clenney, B. F., \& Stephen Taylor, G. (2009). Human resource practices, job embeddedness and intention to quit. Management Research News, 32, 205-219. https://doi.org/10.1108/01409170910943084

Brotheridge C. M. and Grandey A. A. (2002). Emotional Labor and Burnout: Comparing Two Perspectives of "People Work", Journal of Vocational Behavior, 60(1), 17-39. https://doi.org/10.1006/jvbe.2001.1815

Brotheridge C. M. and Lee R. T. (2003). Development and validation of the Emotional Labor Scale, Journal of Occupational and Organizational Psychology, 76, 365-379. https://doi.org/10.1348/096317903769647229

Cukur . C.Ş. (2009). The Development of the Teacher Emotional Labor Scale (TELS): Validity and Reliability. Educational Sciences: Theory \& Practice, 9(2), 527-574

Feldman, D. (1994). The decision to retire early: a review and conceptualization. Academy of Management Review, 19(2), 285-311.

Goffman, E. (1969). Strategic Interaction, University of Pennsylvania Press, . Philadelphia.

Grandey, A. (2000). Emotional regulation in the workplace: A new way to conceptualize emotional labor. Journal of Occupational Health Psychology, 5 (1), 95-110.

Grandey, A. A. (2003). When "the show must go on": Surface acting and deep acting as determinations of emotional exhaustion and peer-rated service delivery. Academy of Management Journal, 46(1), 48-96. https://doi.org/10.2307/30040678

Grandey, A. A., Fisk, G. M., Mattila, A. S., Jansen, K. J., \& Sideman, L. A. (2005). Is "service with a smile" enough? Authenticity of positive displays during service encounters. Organizational Behavior and Human Decision Processes, 96(1), 38-55. https://doi.org/10.1016/j.obhdp.2004.08.002 
DOI: http://doi.org/10.4038/kjm.v6i2.7542

Hatfield, E. (1992). "Primitive emotional contagion". Review of Personality and Social psychology, 9(1), 151-77.

Hayes, L. J., O’Brien-Pallas, L., Duffield, C., Shamian, J., Buchan, J., Hughes, F., ... \& Stone, P. W. (2006). Nurse turnover: a literature review. International journal of nursing studies, 43(2), 237-263.

Hinkin, T., \& Tracey, J. (2000). The cost of turnover: putting a price on the learning curve. Cornell Hotel and Restaurant Administration Quarterly, 41(3), 14-21.

Hom, P. W. \& Griffeth, R. W. (1991). Structural Equations Modeling Test of a Turnover Theory: Cross-Sectional and Longitudinal Analyses. Journal of Applied Psychology, 76, 350-366. https://doi.org/10.1037/0021-9010.76.3.350

Hochschild, A. (1979). Emotion work feeling rules and social structure. American Journal of Sociology, 64(2), 195-208.

Hochschild, A. (1983). The managed heart: The commercialization of feeling.

Krausz, M. (1995). Predictors of intentions to leave the ward, the hospital, and the nursing profession: a longitudinal study" journal of Organizational Behavior, 16(3), 277-88. 10.1002/job.4030160308

Morris, J., \& Feldman, D. (1996). The dimensions, antecedents, and consequences of emotional labor. Academy of Management Review, 21(1), 986-1010.

Parasuraman, S. (1989). Nursing turnover: an integrated model. Research in Nursing and Health, 12(4), 267-77.

Price, J., \& Mueller, C. (1986). A causal model of turnover for nurses. Academy of Management Journal, 24(3), 543-65.

Putnam, L., \& Mumby, D. (1993). Organizations,emotion and the myth of rationality”, in Fineman, S. (Ed.), Emotion in Organizations. London.

Schaubroeck, J., \& Jones, J. (2000). Antecedents of emotional labour dimensions and moderators of their effects on physical symptoms. Journal of Organizational Behavior, 21(1), 163-183.

Shaw, J. (2005). Turnover, social capital losses, and performance. Academy of Management Journal, 48(4), 594-606. 
DOI: http://doi.org/10.4038/kjm.v6i2.7542

Smith, P., \& Gray, D. (2000). The Emotional Labour of Nursing: How Student and Qualified Nurses Learn to Care South Bank University.

Steel, R., \& Ovalle, N. (1984). A review and meta-analysis of research on the relationship between behavioral intentions and employee turnover. Journal of Applied Psychology, 69(4), 673-86.

Takase, M. (2010). A concept analysis of turnover intention: implications for nursing management. Collegian, 17(1), 3-12.

Wharton, A., \& Erickson, R. (1993). Managing emotions on the job and at home: understanding the consequences of multiple emotional roles. Academy of Management Review, 18(1), $457-486$.

Zapf, D. (2002). Emotion work and psychological well-being: a review of the literature and some conceptual considerations. Human Resource Management Review, 12(2), 237 68 